Encontro Nacional de

Economia Industrial e Inovação
Indústria e Desenvolvimento Econômico:

desafios e perspectivas

18 a 20 de setembro de 2018

Uberlândia - Minas Gerais

\title{
O CARÁTER SISTÊMICO DO DESENVOLVIMENTO TECNOLÓGICO: UMA APROXIMAÇ̃̃̃O ENTRE A ESCOLA NEOSCHUMPETERIANA E AS VISÕES DE FERNANDO FAJNZYLBER
}

\author{
Andrey Hamilka Ipiranga* \\ Pablo Felipe Bittencourt ${ }^{* *}$
}

\section{Área Temática: 4.3 Sistemas de inovação - nacional, regional, setorial, tecnológico.}

\section{RESUMO}

$\mathrm{O}$ artigo tem por objetivo estabelecer conexões entre a abordagem de Fernando Fajnzylber e elementos da abordagem neoschumpeteriana sistêmica da inovação, como forma de apontar que muitas das noções fundamentais para o desenvolvimento entre elas orbitam nas discussões em diferentes contextos há muito tempo. A estratégia de apresentação no artigo trouxe inicialmente considerações a cerca do conceito síntese neoschumpeteriano de Sistemas Nacionais de Inovação, ressaltando aspectos analíticos e normativos que o fundamentam, e que revelaram similaridade com a abordagem analítica de Fajnzylber. A seguir a análise sobre as causas do que Fajnzylber chamou de "industrialização trunca" foram apresentadas, ressaltando elementos da abordagem sistêmica que lhe são característicos. Na seção 4, as similaridades são sistematizadas. Os resultados revelaram seis aspectos similares: fatores históricos determinantes do desenvolvimento tecnológico; proximidade entre os elementos que sustentam o progresso técnico no longo prazo em ambas as abordagens; a relação do desenvolvimento tecnológico e as "esferas não-econômicas"; a relação entre o desenvolvimento tecnológico e as características idiossincráticas a cada contexto sociopolítico; o formato da atuação estatal pró-ativo; e aspectos setoriais do progresso técnico. Por fim, a seção 5 apresenta as conclusões do trabalho.

Palavras-chave: Desenvolvimento tecnológico; Fernando Fajnzylber; Sistema Nacional de Inovação. Classificação JEL: O11; O25; O38.
ABSTRACT
The article aims at establishing connections between Fernando Fajnzylber 's approach and elements of the neoschumpeterian systemic approach to innovation, as a way of pointing out that many of the fundamental notions for development between them orbit in the discussions in different contexts a long time ago, which, incidentally, continue to influence important debates. The strategy of presentation in the article initially brought some considerations about the concept of neoschumpeteriano synthesis of National Systems of Innovation, emphasizing analytical and normative aspects that support it, and which revealed similarity with the analytical approach of Fajnzylber. Then the analysis of the causes of what Fajnzylber called "truncated industrialization" is presented, emphasizing elements of the systemic approach that are characteristic to him. In Section 4, similarities are systematized. The results revealed six similar aspects: historical factors determining technological development; proximity between the elements that underpin long-term technical progress in both approaches; the relation of technological development and the "non-economic spheres"; the relationship between technological development and

\footnotetext{
* Graduado em Ciências Econômicas pela Universidade Federal de Santa Catarina (UFSC).

** Professor do Departamento de Economia e Relações Internacionais da Universidade Federal de Santa Catarina (UFSC).
} 
idiosyncratic characteristics in each sociopolitical context; the format of proactive state action; and sectoral aspects of technical progress. To conclude, section 5 presents the conclusions of the paper.

Keywords: Technological development; Fernando Fajnzylber; National Innovation System. JEL classification: $\mathrm{O} 11 ; \mathrm{O} 25 ; \mathrm{O} 38$.

\section{INTRODUÇÃ̃O}

A temática do desenvolvimento tecnológico ocupa espaço de destaque na análise do desenvolvimento em perspectiva histórica das sociedades, estando presentes nos escritos de grandes economistas eternizados por suas contribuições acerca dos fenômenos da produção e da distribuição, e como esses se manifestam em contextos sociopolíticos particulares ${ }^{1}$. Joseph Schumpeter foi quem colocou o desenvolvimento tecnológico no centro da análise. As "novas combinações" de materiais e forças seriam o fator por trás das transformações dinâmicas e estruturais do sistema econômico, logo, as transformações qualitativas em sua totalidade que ocorrem ao longo do tempo (SCHUMPETER, 997).

A centralidade do desenvolvimento tecnológico manifesta-se também nas contribuições da Comissão Econômica para a América Latina (CEPAL) e dos teóricos ligados a ela ${ }^{2}$. Em poucas palavras, os escritos resultantes dessas contribuições defendiam que a incorporação de tecnologia via acumulação de capital, a qual por sua vez seria fruto de um processo de industrialização empregado sob a liderança dos estados nacionais, levariam ao aumento da produtividade do trabalho e do capital, e, em última instância, ao aumento do bem-estar social (WELTERS, 2004). Daí a importância de debruçar-se sobre as formas nacionais particulares em que o progresso tecnológico se revela e se desenvolve.

Objetos desse artigo, duas abordagens importam, sendo que uma é derivada diretamente das contribuições de Schumpeter e a outra do marco teórico cepalino: a primeira, de certa forma, sintetizada no conceito de Sistemas Nacionais de Inovação (SNI), que prima por estabelecer um referencial à análise das formas e características dos processos (historicamente determinados) de inovação em cada país, enfatizando-se a forma como países absorvem utilizam e geram conhecimentos economicamente úteis, levando em conta conjunto de atores específicos a cada estrutura sociopolítica; e a segunda relacionada às contribuições do pesquisador chileno Fernando Fajnzylber, que, partindo do estruturalismo "clássico" cepalino, faz uma análise em perspectiva histórica sobre o processo de industrialização latino-americano, destacando elementos claramente alinhados à perspectiva sistêmica (ainda formalmente inexistente à época), a qual levava a uma agenda normativa baseada na superação de debilidades, em prol da geração endógena de progresso técnico.

Ambas as abordagens nasceram na década de 1980, período marcado pela ascensão da ideologia neoliberal e pela defesa de ajustes recessivos macroeconômicos de curto prazo que se revelaram capazes de relegar a um segundo plano o debate sobre políticas de desenvolvimento de longo prazo, foco de Fajnzylber e da perspectiva sistêmica neoschumpeteriana. A aparente coincidência histórica da emergência dessas duas abordagens mostra a aproximação de Fajnzylber às ideias schumpeterianas, no que diz respeito a sua análise do processo de industrialização latino-americano. Desta forma, o trabalho busca elencar alguns pontos de convergência entre ambas as abordagens, os quais revelam a visão sistêmica da inovação em Fajnzylber. Partindo disso, as seções 2 e 3 abordam, respectivamente, os aspectos positivos e normativos do conceito de Sistemas Nacionais de Inovação, a seção 4 faz uma síntese comparativa dos pontos de convergência e divergência entre essa perspectiva e a análise de Fajnzylber, e, a seção 5 apresenta as conclusões deste trabalho.

\section{A ABORDAGEM DE SISTEMAS NACIONAIS DE INOVAÇÃO}

\footnotetext{
${ }^{1}$ Entre os grandes estudiosos da Economia Política que destacam o tema da tecnologia em seus escritos, podem ser citados Smith (1996), Ricardo (1996) e Marx (2011).

2 Tais contribuições compõe o paradigma conhecido na literatura como "Estruturalismo Latino-Americano" (RODRIGUEZ, 2009).
} 
De forma resumida, a abordagem dos Sistemas Nacionais de Inovação está inserida no escopo da economia neoschumpeteriana ${ }^{3}$ e consiste em "um meio de compreensão sobre o impacto das organizações e instituições da atividade inovativa nacional, entendida como o resultado de processos interativos determinados por vários atores e pelas condições estruturais." "4 Abaixo segue-se o tratamento analítico e normativo do conceito.

\subsection{ORIGENS DO CONCEITO E UM BREVE DELINEAMENTO TEÓRICO}

A gênese do conceito de SNI remete à década de 1980, com a publicação de trabalhos seminais acerca da temática do desenvolvimento tecnológico, que se distanciavam das visões convencionais. Shariff (2006) destaca que o conceito foi formulado simultaneamente nas esferas acadêmica e policymaking (com destaque para a Organização para a Cooperação e Desenvolvimento Económico, doravante OCDE), muito pelo fato dos principais proponentes do conceito ocuparem posições tanto em universidades quanto em organizações fomentadoras de políticas econômicas ${ }^{5}$. Fora à época uma reação ao papel reduzido relegado ao conhecimento, à tecnologia e ao progresso tecnológico pelo paradigma neoclássico, prevalecente no período. Tal enfoque "equilibrista" acerca do crescimento econômico anula ou limita a formas esquemáticas excessivamente simplistas, fatores considerados determinantes ao progresso técnico como a formação e evolução histórica das estruturas socioeconômicas particulares a cada país, o papel do governo e das instituições, a incerteza inerente ao processo inovativo, o aprendizado interativo e, principalmente, o papel da inovação como força motriz do crescimento econômico (SHARIFF, 2006; CASSIOLATO; DE MATOS; LASTRES, 2014).

A pedra angular do conceito de SNI, em termos analíticos, é a interpretação sistêmica do desenvolvimento tecnológico. O primeiro aspecto dessa interpretação é que, ao invés de ser um processo linear, cujos estágios seriam sequencialmente determinados e construídos por ações isoladas de atividades de pesquisa, o progresso tecnológico estaria relacionado à forma como os agentes econômicos interagem entre si em seus processos de inovação. Nessa perspectiva o fator central reside na forma como ocorrem as interações entre a vasta gama de atores sociais existentes, como por exemplo, pesquisadores, firmas, consumidores, instituições de ensino, a partir da qual surgem novos conhecimentos economicamente úteis. Nesses processos não apenas o conhecimento chamado "formal" (via P\&D, e centros de pesquisa e universidades) é determinante para o desenvolvimento tecnológico, mas também outros de natureza tácita e complexa que emergem, por exemplo, experiências e relações profissionais e pessoais, rotinas organizacionais e nas linhas de produção (BALZAT, 2002; CASSIOLATO; DE MATOS; LASTRES, 2014).

O segundo aspecto desta interpretação consiste no fato que os processos interativos de inovação são moldados pelo ambiente institucional em que os atores sociais estão inseridos ${ }^{6}$. Como essas interações ocorrem entre uma vasta gama de atores inseridos em um mesmo contexto sociopolítico particular, o desenvolvimento tecnológico seria influenciado não só por aquelas diretamente relacionadas com o aprendizado formal, mas também com o amplo conjunto de esferas institucionais em tal ambiente, como por exemplo, o sistema educacional (que promove a construção de capacidades criativas e o aprendizado formal), o sistema jurídico-legal (o qual, por exemplo, define questões como direitos de propriedade intelectual e transferência de tecnologia), o sistema financeiro (que por sua vez está

\footnotetext{
3 "Neo-Schumpeterian Economics deals with dynamic processes causing qualitative transformation of economies driven by the introduction of innovation in their various and multifaceted forms and the related co-evolutionary processes." (HANUSCH; PYKA, 2006, p. 280).

${ }^{4}$ Tradução livre de the "[...] a means to learn about the impact of organizations and institutions on national innovative activity understood as the result of interactive processes determined by various actors and framework conditions." (BALZAT, 2002, p. 11).

5 Por exemplo, Christopher Freeman trabalhou como consultor da OCDE na década de 1980 e Bengt-Åke Lundvall ocupou a posição de vice-diretor do Directorate for Science, Technology and Industry (Diretoria de Ciência, Tecnologia e Indústria, em tradução livre) da OCDE (SHARIFF, 2006).

${ }^{6}$ Aqui vale destacar a definição de "sistema" dentro do conceito colocado por Nelson (2005, p. 40), a qual consistem em "um conjunto de atores institucionais que, em conjunto, desempenha o importante papel de influenciar uma performance inovadora."
} 
relacionado com a provisão de crédito para o desenvolvimento de novas tecnologias), e os órgãos formuladores de política econômica (os quais definem a estratégia de desenvolvimento a ser seguida, bem como os parâmetros de tal estratégia materializados nas políticas a serem implementadas). Aqui merece destaque o caráter nacional do desenvolvimento tecnológico, visto que, como destaca Lundvall (2016), as proximidades geográfica, cultural e linguística, bem como a atuação dos governos nacionais e as capacidades tecnológicas construídas historicamente em cada país são fatores que tem efeito positivo sobre as interações entre os agentes presentes em determinado sistema.

Três contribuições merecem destaque na construção do conceito de SNI. A primeira delas é a de Christopher Freeman e a sua abordagem "histórica" sobre o desenvolvimento tecnológico ${ }^{7}$. Neste sentido, Freeman argumenta que os incentivos deliberadamente promovidos pelos estados nacionais ao longo da história à assimilação e produção de tecnologia, bem como o aprendizado tecnológico, e que fatores além do $\mathrm{P} \& \mathrm{D}$ formal (como inovações incrementais que surgem nas linhas de produção e as interações entre firmas e o mercado) foram fundamentais para o desenvolvimento tecnológico e econômico dos países analisados (FREEMAN; SOETE, 2008; BITTENCOURT, CÁRIO, 2017). A segunda contribuição é a de Richard Nelson e a perspectiva "restrita". O enfoque neste caso seriam basicamente os fatores de estímulo "explícito" à performance inovadora das firmas, representados pelas políticas nacionais de ciência e tecnologia, sendo que os elementos que compõe o sistema nacional de inovação de cada país seriam, por exemplo, laboratórios públicos de pesquisa e o provimento de fundos ao desenvolvimento de P\&D em empresas privadas e para pesquisas universitárias (NELSON, 2005; CASSIOLATO; DE MATOS; LASTRES, 2014; BITTENCOURT; CÁRIO, 2017). Por fim, a terceira seria a perspectiva "ampla", fruto das contribuições de Bengt-Åke Lundvall. Nesta abordagem o core do SNI seria o ambiente de interação entre produtores e usuários com a infraestrutura do conhecimento, por onde flui uma série de informações que vão além de, meramente, dados sobre preços e quantidades ${ }^{9}$, ambiente esse que se estende para além da dimensão "restrita", englobando a vasta gama de esferas institucionais existentes (LUNDVALL, 2016; BITTENCOURT; CÁRIO, 2017).

Sendo assim, o conceito de Sistema Nacional de Inovação pode ser considerado um constructo analítico que visa compreender os fatores determinantes do desenvolvimento tecnológico, sendo que o mesmo transcende àqueles mais diretamente relacionados com o fomento à ciência e tecnologia, mas também abarca todas as esferas institucionais presentes em determinado contexto sociopolítico e as relações entre os atores existentes em tal ambiente. Seguindo Lundvall et al. (2007), o conceito seria então um "dispositivo de foco" para a análise da dinâmica da produção e inovação contemporâneas, ou seja, um referencial analítico, com raízes históricas, capaz de captar como os fenômenos socioeconômicos e a institucionalidade presente em cada contexto nacional influenciam os processos de inovação e aprendizado, o que por sua vez ajudam a explicar o desenvolvimento econômico dos países.

\subsection{A AGENDA DE POLÍTICAS DE PROMOÇÃO DO DESENVOLVIMENTO TECNOLÓGICO BASEADAS NO ENFOQUE SISTÊMICO}

Partindo do que foi exposto, fica evidente que há importância do papel do Estado como entidade promotora de políticas voltadas à impulsionar o desenvolvimento tecnológico dos países.

\footnotetext{
7 A análise de Christopher Freeman tem influência direta de Friedrich List (1986) e a sua investigação acerca do desenvolvimento econômico alemão no século XIX, e de seus estudos sobre o chamado "sucesso japonês" observável a partir da década de 1950 (FREEMAN; SOETE, 2008)

8 A abordagem "restrita" tem como base o seu esforço empregado na elaboração de National Innovation Systems: A Comparative Analysis (1993), no qual consiste em uma análise sobre os sistemas nacionais de inovação de 15 países, estratificados em grandes países industrializados e de renda elevada, países pequenos de renda elevada e forte matriz de recursos naturais e países de industrialização recente e níveis inferiores de renda.

9 Tal fluxo de informações está relacionado coma a emergência de conhecimentos não-científicos, e elementos como cooperação, lealdade, coordenação, confiança, poder e códigos de respeito mútuo, os quais seriam indispensáveis para que a incerteza presente no processo inovativo fosse superada. Portanto considera-se, para além do aprendizado "formal" (via P\&D, e centros de pesquisa e universidades), o aprendizado que decorre do uso de inovações as quais demandam longos períodos de utilização (learning-by-using) o aprendizado via melhoras implementadas nos ambientes de produção (learning-by-doing), e as inovações de produtos que emergem da interação entre usuários e produtores (learning-by-interacting) (LUNDVALL, 2016; BITTENCOURT, CÁRIO, 2017).
} 
De uma forma mais abrangente, seguindo a tipologia proposta por Ferraz, Paula e Kupfer (2013), a política industrial ${ }^{10}$ pela Ótica da Competência para Inovar revela-se bastante alinhada com a perspectiva sistêmica da inovação. A atuação estatal se materializa na construção de um ambiente competitivo para as firmas, no desenvolvimento de capacitações (o que por sua vez abrange o desenvolvimento de novas tecnologias e a aquisição de conhecimentos formais e tácitos), e ao estímulo a interações entre firmas, utilizando instrumentos seletivos e gerais, que, respectivamente, afetam grupos específicos de firmas e os agentes econômicos em sua totalidade.

Mais especificamente sobre a caracterização de uma "agenda tecnológica", Cassiolato e Erber (1997), autores reconhecidamente alinhados à perspectiva sistêmica, definem a agenda NeoDesenvolvimentista como aquela que propõe transformações estruturais nas matrizes produtivas na direção dos setores de mais alto grau tecnológico, transformações estas lideradas pelo Estado, e cuja atuação leva em consideração o caráter sistêmico da inovação, o conjunto de agentes envolvidos, e associações estratégicas entre Estado e segmentos civis. Na defesa da eficácia dessa agenda, recorreram a exemplos internacionais e destacaram que as políticas implementadas pelos principais países da OCDE (EUA, Japão, Alemanha e Reino Unido), os quais são considerados desenvolvidos em termos tecnoprodutivos, alinhavam-se a essa agenda Neo-Desenvolvimentista ${ }^{11}$, mesmo que a visão dominante na conjuntura dos 80 's e 90 's não corroborasse esse fato ${ }^{12}$.

Sobre o escopo das políticas de inovação mais contemporâneas, a citação a seguir revela que esse enfoque se fortaleceu na década seguinte, com destaque para:

[...] a tendência de as políticas focalizarem conjuntos de atores e seus ambientes, visando potencializar, disseminar e fazer com que seus resultados sejam mais eficazes. Os diferentes contextos, sistemas cognitivos e regulatórios e formas de articulação, de cooperação e de aprendizado interativo entre agentes são reconhecidos como fundamentais na geração, aquisição e difusão de conhecimentos, particularmente aqueles que são tácitos. Paralelamente, assiste-se ao desenvolvimento de instrumentos que abarcam estes atores coletivos, em complementação à tradicional ênfase a atores individuais. (CASSIOLATO; LASTRES, 2005, p. 39).

Suzigan e Furtado (2010), seguindo o enfoque neoschumpeteriano ${ }^{13}$, colocam que a política industrial seria responsável por:

a) Estabelecer metas para que as novas tecnologias tornem-se competitivas internacionalmente, garantindo que as mesmas alcancem os níveis de economia de escala e eficiência industrial para tal;

\footnotetext{
${ }^{10}$ Em um primeiro momento, define-se política industrial como sendo "[...] o conjunto de incentivos e regulações associadas a ações públicas, que podem afetar a alocação inter e intraindustrial de recursos, influenciando a estrutura produtiva e patrimonial, a conduta e o desempenho dos agentes econômicos em um determinando espaço nacional. (FERRAZ; PAULA; KUPFER, 2013, p. 313).

${ }^{11}$ Aqui se torna evidente a forte influência da análise histórica da agenda Neo-Desenvolvimentista. Nesse sentido, podem ser citados como exemplos: a orientação geral da política industrial alemã passar a ser o upgrade na matriz produtiva nacional, através de estímulos direcionados a investimentos em P\&D naqueles segmentos relacionados ao "paradigma microeletrônico"); as medidas colocadas em prática pelos EUA para transferir os resultados das pesquisas militares a segmentos civis (o que por sua vez tiveram influência positiva e direta no desenvolvimento de setores de mais alto grau tecnológico, como por exemplo, a indústria de semicondutores); e a atuação do MITI (Ministry of International Trade and Industry) japonês na formulação de políticas tecnológicas e industriais de longo prazo a partir de sistemas de previsão tecnológica, cujo objetivo mor seria “[...] identificar aquelas novas tecnologias que são capazes de transformar padrões existentes de crescimento econômico, como foi o caso do reconhecimento da importância da tecnologia da informação.” (CASSIOLATO; ERBER; 1997; p. 56).

12 “....] mesmo durante o auge do neoliberalismo, os Estados jamais deixaram de intervir fortemente para fomentar o desenvolvimento produtivo e tecnológico e a expansão de setores estratégicos para a dinâmica estrutural, mesmo que estas políticas fossem camufladas por imperativos estratégico-militares" (CASSIOLATO; LASTRES, 2005, p. 38).

13 "Segundo essa perspectiva, a política industrial é ativa e abrangente, está orientada a setores ou atividades industriais indutoras de mudança tecnológica e ao ambiente econômico e institucional em seu conjunto, que condiciona a evolução das estruturas de empresas e indústrias e da organização institucional, inclusive a formação de um sistema nacional de inovação." (SUZIGAN; FURTADO, 2010, p. 195).
} 
b) Articular instrumentos, normas e regulamentações (incentivos fiscais, defesa da concorrência, financiamento) de forma sincronizada e sem ambiguidades, estando em confluência com a estratégia definida a fim de promover a competitividade e o desenvolvimento;

c) Construir e colocar em prática serviços de infraestrutura econômica e no desenvolvimento dos sistemas de ensino, ciência, inovação e tecnologia, sempre de forma interconectada com as empresas, para que estas possam desfrutar dos avanços tecnológicos desenvolvidos;

d) Coordenar as ações postas em prática, o que possui grande importância devido ao fato que a coordenação da PI nesta abordagem é ex ante, e não ex post, ou seja, de forma reativa às falhas de mercado ${ }^{14}$;

O enfoque neoschumpeteriano se torna mais robusto como arcabouço analítico para a formulação de políticas de promoção do desenvolvimento tecnológico quando a (suposta) contradição entre políticas de caráter vertical e caráter horizontal ${ }^{15}$ é colocada no centro da discussão sobre ações estatais, que visam o aprimoramento e a atualização tecnológica da estrutura produtiva. Tomando isso como ponto de partida, Gadelha (2001) defendeu que a ação do Estado deveria ser simultaneamente sistêmica e estrutural. A base para esta proposta é a interpretação de que as empresas estão inseridas em um sistema, logo, um locus onde ocorrem interações entre os atores existentes ${ }^{16}$, e que, ao mesmo tempo, estão presentes setores produtivos cujas transformações estruturais e dinâmicas ocorrem de formas distintas, caracterizando assim uma estrutura produtiva heterogênea e idiossincrática, com suas características delimitadas a nível nacional. Logo, o caráter sistêmico se traduz nas transformações no ambiente em que as empresas estão inseridas, e o caráter estrutural das ações estatais devem se direcionar para aqueles setores que "irradiam" os efeitos do avanço tecnológico pela estrutura produtiva em sua totalidade, ou seja, setores que possuem impacto sistêmico. Sendo assim, chega-se a uma nova definição de política industrial, a qual consiste no:

“[...] foco da intervenção pública na dinâmica de inovações da indústria, visando promover transformações qualitativas na estrutura produtiva e o desenvolvimento das economias nacionais, mediante ações sistêmicas que alteram, seletivamente, os ambientes competitivos em que se formam as estratégias empresariais." (GADELHA, 2001, p. 161).

Portanto, a formulação e aplicação de políticas alinhadas à abordagem de Sistemas Nacionais de Inovação possuem o potencial de promover o desenvolvimento tecnológico das nações, à medida que focam em: propiciar a articulação de instrumentos com a capacidade de criar e regular o ambiente competitivo no qual as firmas nacionais estão presentes; promover estímulos à interação e à cooperação entre os atores sociais das mais diversas esferas institucionais, o que por sua vez implica em uma relação simbiótica entre Estado e segmentos privados tendo-se como foco a ampliação das capacidades tecnológicas dos mesmos; criar capacidades inovativas através do estímulo aos aprendizados "formal" e "informal", o que por sua vez está diretamente relacionado com a construção de uma infraestrutura do conhecimento (composta pelos sistemas de ciência, tecnologia e inovação, e pelo sistema de educação, mas também de outras como a de infraestrutura e mesmo de instituições informais como as de confiança entre os agentes) interconectada com o ambiente empresarial; e a promoção de setores dinâmicos com o potencial de irradiar os efeitos de seus avanços tecnológicos por toda a malha produtiva.

\footnotetext{
${ }^{14}$ Como colocam Ferraz, Paula e Kupfer (2013) a política industrial pela Ótica das Falhas de Mercado seria aquela aplicada apenas em situações de funcionamento subótimo dos mecanismos de mercado, situações essas onde estariam operando as chamadas "falhas de mercado" (como por exemplo, externalidades e bens públicos). A PI atuaria no sentido de minimizar os efeitos negativos causados por tais fenômenos.

15 “As políticas industriais horizontais são aquelas que buscam melhorar o desempenho da economia na sua totalidade, sem privilegiar alguma indústria específica. [...] Já as políticas industriais verticais privilegiam deliberadamente uma indústria específica. Ou seja, a partir de decisões estratégicas, o Estado mobiliza parte dos instrumentos anteriormente descritos, focalizando e privilegiando um conjunto de empresas, indústrias ou cadeias produtivas.” (FERRAZ; PAULA; KUPFER, 2013, p. 320).

${ }^{16}$ Resgata-se aqui o que foi discutido na subseção anterior sobre Sistemas Nacionais de Inovação.
} 
Dito isso, passamos a seguir para uma breve apresentação daquilo que Fajnzylber chamou de industrialização trunca da América Latina, como forma de destacar os elementos alinhados à perspectiva sistêmica.

\section{A INDUSTRIALIZAÇÃO TRUNCA}

As contribuições de Fernando Fajnzylber estão inseridas no marco teórico cepalino, mais precisamente no chamado "Neo-Estruturalismo Latino-Americano"17, as quais se posicionam de forma crítica e complementar às originais desse marco teórico. Abaixo são apresentadas as bases do pensamento estruturalista e suas considerações e limitações a cerca do progresso tecnológico. Seguem-se a isso os aspectos positivos e normativos em Fajnzylber.

\subsection{FUNDAMENTOS DO ESTRUTURALISMO LATINO-AMERICANO: A QUESTÃO DA TECNOLOGIA NO CENTRO DO DEBATE.}

O processo de industrialização e suas características sempre estiveram no centro da concepção do Estruturalismo Latino-Americano. Partindo das características ${ }^{18}$ estruturais das economias latinoamericanas e suas implicações derivadas, o processo seria "[...] o único meio que dispõem para ir captando uma parte do fruto do progresso técnico e elevando progressivamente o nível de vida das massas." (PREBISCH, 2011, p. 96).

A industrialização nessa perspectiva pode ser encarada de duas formas: como um processo, historicamente determinado, e que se traduz na ascensão e liderança do setor industrial nas nações latinoamericanas, fato ocorrido ao longo do século XX pelo que ficou conhecido como o Processo de Substituição de Importações (PSI); e como um modelo (Modelo de Substituição de Importações) ${ }^{19}$, ou seja, uma abstração de características da materialidade, busca captar os aspectos essenciais e a lógica de desenvolvimento de tal processo, fundamentando a elevação do padrão de vida da população no incremento da produtividade derivada do aumento da dotação capital-trabalho (através da adoção e o emprego eficaz de métodos de produção indiretos) e do aumento da densidade de capital (com a acumulação impulsionada pelo progresso técnico (FONSECA, 2003; RODRIGUEZ, 2009; PREBISCH, 2011). A característica principal do Modelo de Substituição de Importações, de forma resumida, é a sua dinâmica marcada pela contradição entre a elevação da produção substitutiva e os limites da capacidade de importar, e a continuidade da produção substitutiva é limitada pelo estrangulamento externo e pela tecnologia disponível (o que está relacionado com as características estruturais dos países periféricos) ${ }^{20}$ (TAVARES, 2011).

A problemática da tecnologia no que tange o Modelo de Substituição de Importações deriva de limitações do mesmo, manifestado no desenvolvimento historicamente observado das economias latinoamericanas. Ao contrário dos países desenvolvidos, onde foram criadas as técnicas modernas de produção e cujo domínio foi restringido a tal círculo de nações ${ }^{21}$, os sistemas produtivos de países periféricos foram

\footnotetext{
17 O Neo-Estruturalismo pode ser entendido em poucas palavras como a fase mais recente de evolução do Estruturalismo Latino-Americano, o qual pode ser datado a partir da década de 1990, e que "recupera a agenda de análises e de políticas de desenvolvimento, adaptando-a aos novos tempos de globalização" (BIESLCHOWSKY, 2000, p. 63).

${ }^{18}$ Sobre a concepção do sistema Centro-Periferia e os temas de análise derivados do mesmo ver Rodriguez (2009) e Prebisch (2011).

${ }^{19}$ A expressão "substituição de importações" pode ser definida como "Um processo de desenvolvimento interno que tem lugar e se orienta sob o impulso de restrições externas e se manifesta, primordialmente, através de uma ampliação de diversificação da capacidade produtiva industrial.” (TAVARES, 2011, p. 72).

${ }^{20}$ Dada uma situação inicial de estrangulamento externo, a produção substitutiva inicia-se pelos bens de consumo final, devido ao menor conteúdo tecnológico existente nos mesmos. A partir disso, cria-se uma demanda derivada por bens intermediários e bens de capital, visto o efeito positivo sobre o multiplicador da renda e pelo fato que apenas uma parcela do valor agregado da produção em sua totalidade é internalizada, considerando os resultados da etapa inicial.

${ }^{21} \mathrm{O}$ desenvolvimento observado em perspectiva histórica de tais países mostra que, com a criação e o domínio das técnicas modernas, foi possível que neles houvesse um aumento da densidade de capital em confluência com a sua homogeneização pelos setores existentes. Isso foi possível devido à determinação mútua entre inovações e renda, e também pela substituição de mão-de-obra por capital possibilitada pela absorção de trabalho nos novos processos produtivos criados. Assim, torna-se
} 
impelidos a utilizar técnicas de produção cujo desenvolvimento eles não iniciaram, nem mesmo participaram dos períodos iniciais de desenvolvimento, quando a distância da fronteira tecnológica não é tão significativa. Adicionalmente, a crescente complexidade produtiva limitava a capacidade de promoção de um emparelhamento produtivo e tecnológico, por um lado, no crescimento da escala produtiva em segmentos centrais à acumulação de capital e por outro, na consequente elevada necessidade de capital para levar a cabo as operações nos setores. Aliás, eram esses os setores considerados núcleo tanto da acumulação de capital como da geração e difusão de progresso técnico.

Assim, com o passar do tempo, foi cada vez mais ficando claro que a simples introdução dos setores mais intensivos em capital no parque produtivo, tal como ocorrera entre 1956-61 no Brasil, por meio do Plano de Metas e que depois foi reforçado em certa medida pelo II PND, a esperada geração e difusão do progresso técnico poderiam continuar encontrando entraves significativos. Esse foi o principal foco da visão de Fajnzylber e que apresentamos a seguir.

\subsection{A INDUSTRIALIZAÇÃO "TRUNCA" DA AMÉRICA LATINA: ELEMENTO SCHUMPETERIANOS NA ANÁLISE DE FAJNZYLBER}

O desenvolvimento econômico latino-americano observado entre as décadas de 1940 e 1970 praticamente colapsou com a crise da ordem de Bretton Woods e com os choques do petróleo, ocorridos no terceiro quarto do século XX. A crise econômica global aprofundou-se na década de 1980, e seus efeitos tornaram-se manifestos na América Latina com a forte retração da atividade econômica da região. Fernando Fajnzylber, economista chileno e pesquisador da CEPAL, insere-se no debate sobre tal crise a partir de um diagnóstico fruto da análise histórica da industrialização latino-americana focado no caráter distorcido e "truncado" desse processo de industrialização, o qual se distancia do argumento neoliberal (e a sua defesa da irresponsabilidade fiscal dos estados nacionais como causa da crise econômica na região).

A análise de Fajnzylber tem como ponto de partida os aspectos similares e divergentes que existem entre o processo de industrialização da América Latina e o processo de industrialização dos países desenvolvidos, bem como com a reestruturação produtiva ocorrida nesses e naqueles países denominados Novos Países Industrializados asiáticos (New Industrialized Countries em inglês, ou NICs) ao longo do século XX.

De forma sintética, as grandes potências industriais e os países que experimentaram rápido e significativo crescimento industrial a partir da metade do século XX (com destaque para o Japão) colocaram em prática esforços com vistas à reformatação de suas estruturas produtivas, visto o esgotamento do então padrão industrial vigente marcado pela prevalência dos setores de bens de capital e setor químico, e cujo padrão de consumo estava associado a setores de bens duráveis (enfatizando-se aqui o setor automobilístico). Tal reformatação caminhou na direção de novas tecnologias emergentes, como é o caso da microeletrônica, e que, na perspectiva neoschumpeteriana, marcou a passagem ${ }^{22}$ da "Era do Petróleo, do Automóvel e da Produção em Massa" para a "Era a Informação e Telecomunicações" (o que é observável a partir da década de 1970) (PEREZ, 2009).

Sua conclusão, na forma mais geral, é de que a industrialização latino-americana, construída sob o escopo do Modelo de Substituição de Importações, foi marcada pela ausência de criatividade (conceito esse a ser abordado logo abaixo), ao contrário daqueles países que serviram de parâmetro de comparação para a sua análise.

O elemento a ser destacado é que o padrão de industrialização latino-americano foi marcado pela replicação dos padrões setoriais dos países desenvolvidos, e que, apesar do crescimento do PIB manufatureiro e de sua participação do PIB total da região tenham sido crescentes na maior parte dos países entre 1940 a 1980 (sendo que a partir daí houve uma queda drástica em ambas as variáveis), tal

evidente a relação harmônica entre acumulação, progresso técnico, salários e emprego nos países nos quais as técnicas modernas de produção foram desenvolvidas (RODRIGUEZ, 2009).

${ }^{22}$ A irrupção de um novo padrão tecnológico é conhecida na literatura neoschumpeteriana como "Revolução Tecnológica", a qual consiste em um "conjunto de inovações radicais inter-relacionadas, formando uma grande constelação de tecnologias interdependentes" (tradução livre de "[...] a set of interrelated radical breakthroughs, forming a major constellation of interdependente technologies [...]") (PEREZ, 2009, p. 8). 
replicação mostrou-se inapta à realidade desses países, tanto em termos "econômicos" (aqueles relacionados à esfera produtiva) como "não-econômicos" (ou seja, aqueles relacionados às esferas social, política e cultural). A compreensão dos processos para melhorá-los foi menos seu objeto do que a realização daquilo que já existia. Apesar do crescimento industrial observado, Fajnzylber coloca que as estruturas socioeconômicas dos países latino-americanos continuavam a ter como características marcantes a abundância de mão-de-obra e o predomínio de setores intensivos em recursos naturais, além de que, mesmo com o crescimento industrial observado, a inserção externa via produtos manufaturados mostrava-se limitada, dado que o crescimento das exportações de produtos industrializados foi baixo em relação ao crescimento do PIB industrial (FAJNZYLBER, 1983; PAIVA, 2006).

Sendo assim, Fajnzylber defende que a industrialização deveria ser empregada levando em consideração as características particulares a cada país, tendo como critério de avaliação dos resultados "o grau de funcionalidade para responder às carências sociais majoritárias e a criatividade para desenvolver a gama variada de potencialidades regionais." 23 Partindo disso, o autor elenca uma série de aspectos singulares do processo de industrialização latino-americana que tornam evidente o contraste entre os resultados desses, dos países desenvolvidos e nos NICs (observáveis principalmente entre as décadas de 1950 e 1970). Abaixo são listadas essas características:

i) A prevalência das Empresas Transnacionais (ETs) nos setores dinâmicos da economia em relação ao empresariado nacional público e privado, marcando assim uma vocação industrial precária da região, sem que houvesse regras que pudessem garantir o fortalecimento do processo de inovação tecnológica nacional.;

ii) O chamado "protecionismo frívolo" 24 foi imperante, o qual pode ser definido como aquele que ampara tanto as empresas nacionais como as ETs, com poucos estímulos ao desenvolvimento tecnológico e à competitividade internacional, e que priorizou os setores de bens finais em relação aos setores de bens intermediários e de capital;

iii) O atraso do setor de bens de capital, considerado o setor "portador de progresso técnico" (dado os seus efeitos positivos na produtividade e remunerações do trabalho, bem como no fabrico e na produtividade dos bens de capital em si), o que se torna evidente com a participação marginal desse setor na produção manufatureira da região. Ressalta-se também o fato que a produção de bens de capital de mais alto grau de complexidade estava a cargo das ETs, sendo que a produção das empresas nacionais era voltada àqueles bens de capital de menor complexidade ;

iv) A fragilidade externa da região e do setor industrial, o qual representava a maior parcela do déficit estrutural na Balança Comercial da América Latina e que evidencia o caráter "truncado" do padrão de industrialização latino-americano, o que está relacionado com o fraco desenvolvimento tecnológico observado nesses países, fruto da incapacidade de assimilação e criação de capacidades inovativas, e

v) A inserção externa se deu primordialmente via recursos naturais, o que por sua vez contribuiu para a situação negativa da Balança Comercial da região, visto que a modernização da agricultura ocorreu primordialmente nos setores primário-exportadores (cujos efeitos são manifestos na deterioração dos preços relativos) somada ao aumento da demanda por produtos alimentícios, resultante da intensificação da urbanização que vem a reboque da industrialização.

As particularidades acima elencadas por Fajnzylber o levam a concluir que o padrão de industrialização latino-americano teve como marca o fato dos países da região não conseguirem construir uma matriz produtiva capaz de promover o desenvolvimento tecnológico internamente, caracterizando assim a chamada "industrialização trunca", observada entre as décadas de 1930 e 1980 (tal padrão de industrialização não conseguiu romper com a contradição existente no Modelo de Substituição de

\footnotetext{
${ }^{23}$ Tradução livre de: “[...] el grado de la funcionalidad para responder a las carencias sociales mayoritarias y la creatividad para desarrollar la variada gama de potencialidades regionales.” (FAJNZYLBER, 1983, p. 163).

${ }^{24} \mathrm{O}$ contraponto desse conceito seria o "protecionismo para aprendizagem", o qual marcou o desenvolvimento industrial japonês observado no período pós-guerra (Ibid, 1983).
} 
Importações no que tange a questão da tecnologia). Os fatores que impediram a assimilação das tecnologias dos grandes centros considerando as carências e potencialidades internas de cada país, logo suas características particulares e específicas, provocaram em última instância a incapacidade de se constituir um "núcleo endógeno de dinamização tecnológica", núcleo este que promoveria a geração e assimilação de progresso técnico ${ }^{25}$ levando em consideração as especificidades de cada nação. Esse "núcleo endógeno de dinamização tecnológica" pode ser entendido como uma estrutura produtiva articulada, em que criatividade e aprendizado se retroalimentam, impulsionando o desenvolvimento tecnológico em setores estratégicos, e que se espraiariam por toda a estrutura produtiva através de contínuas ondas de inovações (PAIVA, 2006; RODRIGUEZ, 2009). Objetivando a formação deste núcleo endógeno, Fajnzylber propõe uma "nova industrialização" para a América Latina, a qual se basearia em certas categorias fundamentais do escopo de sua análise.

Visando alavancar o desenvolvimento econômico sustentado de longo prazo dos países latinoamericanos com a superação das debilidades econômicas e sociais de cada país da região, Fajnzylber defendeu que a reestruturação produtiva a ser empregada deveria ser "eficiente". O conceito de "eficiência" de Fajnzylber estava relacionado com o desenvolvimento industrial que combinasse crescimento e criatividade. Já que o conceito de "crescimento" é algo fácil de quantificar, o foco volta-se à necessidade de aprofundar suas considerações a cerca do conceito de "criatividade".

Inserido no conceito de eficiência, a criatividade estaria relacionada basicamente com a superação das debilidades sociais e com a constituição de um novo padrão tecnológico formado nos grandes centros, além do fato que ela transcende o plano "estritamente econômico", tornando-se manifesta nas esferas política, cultural, artística, científica e produtiva, o que em última instância impulsionaria o desenvolvimento das capacidades individuais e coletivas próprias de cada estrutura sociopolítica, evidenciando-se assim o caráter endógeno da criatividade (FAJNZYLBER, 1983; PAIVA, 2006). A conexão entre criatividade e o desenvolvimento industrial pode ser examinada nas palavras de Fajnzylber:

La creatividad puede entonces asociarse al estabelecimento de fines sociales, a la profundización em la comprensión del hombre y de las relaciones sociales, así como del médio natural y de los procesos por médio de los cuales este se transforma. Sin embargo, em el ámbito limitado de estas reflexiones sobre industrialización, la atención se concentra em la discusión de algunos requisitos económico-institucionales de la creatividad y de su vinculación con el proceso de crecimiento. (FAJNZYLBER, 1983, p. 348-349).

A criatividade, portanto, seria a atitude por trás do aprendizado ${ }^{26}$ e que o efetiva, sendo condicionada pelos diversos atores que constituem as esferas da materialidade social, levando em conta as características idiossincráticas tanto em termos "econômicos" e "não-econômicos" de cada país, para que assim as capacidades individuais e coletivas possam ser desenvolvidas (RODRIGUEZ, 2009). O crescimento por si só não seria suficiente para o estímulo à criatividade, sendo que outros fatores são necessários para o desenvolvimento da criatividade interna, como a formatação da relação entre os agentes da atividade econômica e o grau de descentralização da vida econômica, o que propicia um maior grau de autonomia para que a criatividade seja desencadeada através da interação entre os agentes, a nível dos atores responsáveis pelo desenvolvimento tecnológico como dos atores que se situam na esfera produtiva (FAJNZYLBER, 1983; PAIVA, 2006).

Segue-se que a "nova industrialização" de Fajnzylber deveria promover a criatividade, o que por sua vez possibilitaria a geração interna e incorporação externa de técnicas modernas de produção, além de promover a inserção externa através do aumento da competitividade "autêntica" ${ }^{27}$, e colocando que o

\footnotetext{
${ }^{25} \mathrm{O}$ conceito de progresso técnico em Fajnzylber consiste na acumulação de conhecimentos sobre um grupo de bens e a forma de produzi-los, e também a acumulação de conhecimentos relacionados às técnicas de produção existentes.

${ }^{26} \mathrm{O}$ aprendizado é definido por Fajnzylber como sendo a aquisição conhecimentos novos relacionados à técnicas produtivas, os quais surgem a partir do exercício da produção por si só como através da Pesquisa e Desenvolvimento (P\&D) (RODRIGUEZ, 2009).

27 Ou seja, o fortalecimento da competitividade através da geração e difusão de progresso técnico e do aumento da produtividade resultante. Tal fortalecimento seria obtido através de transformações estruturais nas várias esferas institucionais
} 
desenvolvimento tem como fim principal solucionar as carências internas e promover as potencialidades de cada nação (PAIVA; 2006). Fajnzylber não chega a definir uma estratégia completa sobre reestruturação produtiva, mas sugere quatro setores prioritários para a constituição de uma matriz industrial produtiva e articulada, a saber: a indústria automobilística, o setor de bens de capital, o setor agrícola e o setor energético.

O Estado teria papel estratégico à nova industrialização definindo objetivos a partir de demandas sociais, como a definição dos programas de investimentos a serem executados em setores específicos, o que incluía as condições de "equilíbrio macroeconômico" para tal. Além disso, as bases sociais de sustentação dessa agenda seriam resultantes da chamada "nova aliança", composta pelos diversos agentes da materialidade e da convergência dos mesmos para a valorização do nacional (PAIVA, 2006; RODRIGUEZ, 2009). Em resumo:

[...] é a constituição de um "núcleo endógeno de dinamização tecnológica" que determinaria, segundo Fajnzylber, a criação e a articulação de uma matriz industrial e produtiva, capaz de gerar o progresso técnico, tanto através da adaptação do acervo tecnológico adquirido internacionalmente, como pela via da inovação. Com base na existência desse núcleo, a geração, adaptação e incorporação de progresso técnico se transforma em produtividade que leva, por fim, ao aumento da competitividade nos mercados internacionais. (PAIVA, 2006, p. 195).

\section{UMA SÍNTESE PRELIMINAR: ASPECTOS CONVERGENTES E DIVERGENTES ENTRE OS SISTEMAS NACIONAIS DE INOVAÇÃO E AS CONTRIBUIÇÕES DE FAJNZYLBER}

A partir do que foi apresentado, pode-se observar que existe uma proximidade entre a análise de Fajnzylber e da abordagem de SNI, tanto em termos de categorias de análise como em termos de agendas normativas. Essa seção, é um detalhamento dessa similaridade.

Antes disso vale destacar que afinidades analíticas normalmente são explicadas pela aderência, pelo menos em partes, a um mesmo referencial. Nesse caso, a referência é Joseph Schumpeter. Torres (2006), destacara a influência do autor na formação de Fajnzylber, com destaque ao papel da firma como agente econômico inovador, tendo tal influência se manifestado ao longo de seus escritos desde a década de 1970;

Isso ajuda a explicar a parte do processo de refinamento analítico das contribuições da CEPAL nos domínios do desenvolvimento produtivo, tecnológico e da integração internacional no contexto da década de 1990, por ter aproximado autores neoschumpeterianos de Fajnzylber que resultou no que Bielschowsky (2009) denominou de fusão do pensamento neoschumpeteriano ao estruturalista. Em suas palavras:

"The merger of the Schumpeterian and structuralist approaches is not surprising, given the priority both assign to the analysis of historical trends in the productive domain. The neo-Schumpeterian accent on knowledge formation and accumulation through the enterprise learning process, the effect of past decisions on the present (path-dependency), and changes in techno-economic paradigms enhance the historical-structural approach used by eclac in its attempt to understand changes in productive structures under conditions of underdevelopment and structural heterogeneity." (BIESLCHOWSKY, 2009, p. 181).

Com relação ao diagnóstico de Fajnzylber sobre as debilidades da industrialização latinoamericana, é possível fazer uma leitura neoschumpeteriana sobre as particularidades desse processo apresentadas na seção anterior. Sendo assim, os fatores i e ii podem ser analisados sob a ótica do conceito de SNI como a incapacidade se constituir um arcabouço institucional que possibilitasse a construção de

existentes, conscientemente empregadas por meio de políticas industriais, que teriam objetivo de constituir uma base sólida para a inserção internacional (SUZIGAN; FERNANDES, 2004). 
conhecimentos economicamente úteis, seja pela assimilação de técnicas oriundas dos países centrais ou pela formação de capacidades inovativas internas, por meio de esforços voltados ao aprendizado (como, por exemplo, a formação de regras legais que garantissem a transferência e apropriação por parte de empresas nacionais de tecnologias utilizadas pelas ETs, e a construção de um sistema de ciência, tecnologia e inovação que estivesse alinhado aos setores produtivos para o fortalecimento da competitividade externa).

Os fatores iii, iv e v por sua vez se relacionam à literatura neoschumpeteriana através do conceito de "eficiência Schumpeteriana" (MARTINS, 2008), baseado na prescrição de um formato de especialização produtiva e inserção internacional com base na oportunidade, na apropriabilidade e cumulatividade tecnológica. Assim, os padrões de comércio internacional deveriam ser definidos com base nas "oportunidades inovativas" (possibilidade de aperfeiçoamentos e extensões dos aparatos tecnológicos) em um paradigma tecnológico, nas expectativas de apropriação de retornos extraordinários associados a investimentos nas oportunidades tecnológicas possíveis, e na concepção de que os padrões existentes de especialização produtiva e de comércio condicionam os padrões de mudança tecnológica através de externalidades positivas ou negativas, e as oportunidades para a geração de aprendizado tecnológico em maior ou menor grau. Partindo disso, o atraso no setor de bens de capital, considerado estratégico para a industrialização da região, e as implicações desse atraso na frágil inserção internacional dos países latino-americanos, mostram que o padrão de industrialização empregado na região passou ao largo de ser eficiente em termos schumpeterianos.

Já em relação a aspectos analíticos e normativos de fato tanto a análise de Fajnzylber como a perspectiva sistêmica destacam o valor de um amplo conjunto de atores sociais presentes nas mais diversas esferas institucionais de cada contexto sociopolítico específico, bem como as suas interações, como fatores-chave ao avanço tecnológico, sendo que tal entendimento serve de base para a formulação de políticas específicas promotoras do desenvolvimento tecnológico. Abaixo, são apontados alguns pontos de convergência entre ambas as perspectivas:

1) Aspectos históricos determinantes do desenvolvimento tecnológico: tanto em Fajnzylber como na perspectiva analítica de SNI, o desenvolvimento tecnológico é determinado pela forma como as estruturas produtivas e institucionais de diferentes países revelaram configurações próprias ao longo do tempo. Fajnzylber destaca uma grande diferença entre latino-americanos e países centrais, destacando que o formato como foi realizado o processo de industrialização limitou o progresso técnico de forma geral entre os primeiros. Passado praticamente meio século de produção substitutiva, mesmo a internalização de setores considerados intensivos em tecnologia (setores cuja liderança foi substituída a partir, sobretudo, do terceiro quarto do século $\mathrm{XX)}$ não fora suficiente para promover uma forma de produzir que gerasse contínuas inovações, ou seja, a forma de impulsionar a geração de progresso técnico basicamente reproduz as contradições existentes no Modelo de Substituição de Importações. O contraste com os países desenvolvidos é claro, no sentido no qual é possível observar que os mesmos, ao longo de suas histórias, colocaram em prática agendas normativas voltadas ao fortalecimento de capacidades inovativas, políticas essas alinhadas ao enfoque sistêmico da inovação, e que tiveram o objetivo de promover a reestruturação produtiva desses países na direção de setores tecnologicamente mais avançados (em outras palavras, promover o ingresso na revolução tecnológica em curso a partir da década de 1970). Na perspectiva de SNI, a limitação da estrutura produtiva em realizar processos de inovações "sofisticados" está na análise de Viotti (2002), por exemplo. Em termos analíticos, estas limitações residem na incapacidade de incorporar conhecimentos científicos e não-científicos por meio do fortalecimento das interações entre os agentes aos processos de produção e de inovação, o que remeteria a uma característica estrutural, derivada da incapacidade dessa estrutura produtiva de se inserir nas revoluções tecnológicas.

2) Os elementos que sustentam o desenvolvimento tecnológico e o progresso técnico no longo prazo encontram similaridade em Fajnzylber e na perspectiva sistêmica: Em Fajnzylber a geração e difusão de progresso técnico passam pelo estímulo à criatividade, indo além do simples crescimento em termos quantitativos. Portanto, o desenvolvimento tecnológico passaria 
pelo estímulo às capacidades individuais e coletivas relacionadas a cada contexto sociopolítico específico, levando em consideração as carências e potencialidades dos mesmos, o que por sua vez possibilita o aprendizado, ou em outras palavras, a aquisição de conhecimentos sobre as técnicas de produção. $\mathrm{Na}$ abordagem de SNI, o aprendizado, tanto em termos "formais" e nãoformais", seria a variável-chave para a promoção do desenvolvimento tecnológico. Através da criação de fluxos de conhecimentos "científicos" e "não-científicos" oriundos de processos como learning-by-searching, learning-by-doing, learning-by-using e learning-by-interacting, os quais por sua vez possuem uma relação íntima com as inter-relações existentes entre os atores que compõe a realidade social, o desenvolvimento tecnológico não é só possível, mas se torna efetivo.

3) As "esferas não-econômicas" e o desenvolvimento tecnológico: destaca que o desenvolvimento tecnológico transcende a esfera "estritamente econômica". Fajnzylber coloca que as esferas culturais, artística, política, científica e produtiva, bem como os pontos de encontro entre essas esferas, são fatores que condicionam o estímulo à criatividade, além de outros, como o grau de descentralização da vida econômica e a natureza da relação entre os agentes. O escopo da análise de SNI também abarca um conjunto diverso de elementos não econômicos capazes de explicar o desenvolvimento tecnológico. Isso se revela em análises específicas dos diversos países, como o destaque de Christensen et.al. (2008) à relação de confiança entre produtores e usuários para a rápida difusão de inovações no SNI dinamarquês, ou características particulares da mentalidade dos trabalhadores de um país (KIM, 2005);

4) $\mathrm{O}$ desenvolvimento tecnológico e as características idiossincráticas a cada contexto sociopolítico: O ponto inicial da análise de Fajnzylber seriam as carências e potencialidades internas dos países da América Latina e da região como um todo, o que se torna evidente nos aspectos particulares do processo de industrialização latino-americano, sendo que é considerado todo o conjunto de atores particulares e suas características. Fajnzylber postula que a criatividade e, em última instância, o desenvolvimento tecnológico, tem uma relação direta com os aspectos idiossincráticos de cada país, o que por sua vez torna evidente o caráter endógeno do escopo de sua análise sobre os determinantes do progresso técnico. Os autores alinhados com a perspectiva de SNI, por sua vez, ressaltam que certos aspectos definidos em âmbito "nacional" são fatores que influenciam positivamente as interações entre os agentes e, por conseguinte, o desenvolvimento tecnológico, como proximidades cultural, geográfica e linguística presentes em um país, bem como o desenvolvimento das capacidades tecnológicas historicamente construídas pelos países;

5) O formato da atuação estatal pró-ativo: o papel do Estado em Fajnzylber se traduz principalmente em sua proposta de "nova industrialização". Nela, a atuação estatal se traduz na construção da estratégia nacional de desenvolvimento como um todo, através da promoção de investimentos nos setores considerados estratégicos e a manutenção do "equilíbrio macroeconômico" para a execução dessa estratégia, por exemplo. A "nova aliança" seria a base de sustentação dessa proposta normativa, na qual a estratégia definida seria levada a cabo alicerçada em uma conexão entre os agentes da materialidade social, como grupos empresariais, burocracia estatal e classe trabalhadora. A atuação do estado na abordagem de SNI ocorreria no sentido de, de forma resumida, construir um habitat favorável para às interações entre os agentes (logo, um ambiente propício para o desenvolvimento do aprendizado) e à criação de capacidades inovativas, no que diz respeito à assimilação e geração de novas tecnologias como ao aprendizado em si. Em SNIs com elevadas carências como os latino-americanos, a ação estatal, consequentemente, teria que ser mais proeminente. A sua atuação pró-ativa, na perspectiva neoschumpeteriana, é tratada por Mazzucato (2014), a qual, partindo das experiências históricas dos países tecnologicamente desenvolvidos, postula que é a relação simbiótica entre Estado e segmentos privados da esfera produtiva que impulsiona o capitalismo e o desenvolvimento, indo de encontro com a visão dicotômica comumente difundida sobre a relação entre esses dois atores da realidade social; 
6) A preferência por um conjunto de produtos e setores, segundo suas propriedades de absorver e gerar progresso técnico: Nesse aspecto, Fajnzylber alinha-se a noção de eficiência Schumpeteriana, tanto quando nota que a inserção externa mantinha-se demasiadamente baseada em produtos intensivos em recursos naturais, ou seja, de restrita capacidade de gerar aumentos de produtividade no longo prazo, como pelo fato de apontar um conjunto de setores que seriam capazes de constituir uma matriz industrial produtiva e articulada que, por guardarem melhores condições relativas de induzir processos produtivos criativos seriam objetos dos incentivos estatais. Na perspectiva sistêmica, tais condições são as de apropriabilidade dos ganhos da inovação, cumulatividade da base técnica de conhecimentos e oportunidades de aperfeiçoamentos e extensões das tecnologias existentes, e seriam as promotoras da eficiência Schumpeteriana. Vale considerar que em termos de agenda normativa, a promoção de políticas voltadas ao fortalecimento de capacidades inovativas estaria voltada de forma confluente à eficiência Schumpeteriana àqueles setores com impacto sistêmico potencial.

Foram apresentadas acima nossas percepções relativas à aproximação das análises de Fajnzylber e da perspectiva de Sistemas Nacionais de Inovação. Apesar do objeto de estudo de cada perspectiva ser distinto (Fajnzylber trata do desenvolvimento dos países latino-americanos e a perspectiva sistêmica, por sua vez, trata dos países tecnologicamente desenvolvidos), o trabalho mostrou que existem claras proximidades entre ambas as abordagens. Para além da defesa da centralidade existente do progresso tecnológico nos processos de desenvolvimento econômico historicamente construídos, é evidente que tanto a defesa da influência de fatores extraeconômicos como a centralidade do papel do Estado são pontos de convergência. Observou-se ainda proximidade entre a "criatividade" de Fajnzylber e o "aprendizado" na análise neoschumpeteriana, no que tange suas causas e particularidades, sobretudo a influência de fatores extraeconômicos, que, por sua vez, podem ser resumidos como as arquiteturas institucionais construídas e delimitadas pelas idiossincrasias de cada sistema (especialmente quando se trata do caráter "nacional" dessas estruturas institucionais). Por fim, o "núcleo endógeno de dinamização tecnológica" sintetiza as similaridades existentes, pois o mesmo preconiza a articulação simbiótica entre estrutura produtiva e ambiente institucional tal qual a perspectiva de Sistemas Nacionais de Inovação. Abaixo segue um quadro que sintetiza o que foi apresentado.

Quadro 1 - Quadro-síntese dos pontos de convergência nas abordagens de Fajnzylber e de SNI

\begin{tabular}{|c|c|c|}
\hline & $\begin{array}{c}\text { Aspectos analíticos e normativos } \\
\text { em Fajnzylber }\end{array}$ & $\begin{array}{l}\text { Aspectos analíticos e normativos em } \\
\text { SNI }\end{array}$ \\
\hline $\begin{array}{c}\text { Aspectos históricos } \\
\text { determinantes do } \\
\text { desenvolvimento } \\
\text { tecnológico }\end{array}$ & \begin{tabular}{|c|} 
Diagnóstico em perspectiva histórica do \\
processo de industrialização latino- \\
americana torna evidente a incapacidade \\
de assimilação e geração de progresso \\
técnico derivada das características \\
adquiridas pela estrutura industrial como \\
fruto do PSI. Daí a necessidade de \\
promoção da criatividade. \\
\end{tabular} & $\begin{array}{l}\text { Cumulatividade dos conhecimentos adquiridos } \\
\text { pelo SNI é elemento decisivo à compreensão de } \\
\text { suas possibilidades futuras. O desenvolvimento é } \\
\text { path dependent. Daí a conveniência de promover } \\
\text { o fortalecimento das interações entre os agentes } \\
\text { ao longo do tempo, o que, aliás, vê-se das } \\
\text { agendas de promoção de desenvolvimento } \\
\text { tecnológico nos SNIs mais desenvolvidos. }\end{array}$ \\
\hline
\end{tabular}




\begin{tabular}{|c|c|c|}
\hline $\begin{array}{c}\text { Os elementos que } \\
\text { sustentam o } \\
\text { desenvolvimento } \\
\text { tecnológico e o progresso } \\
\text { técnico no longo prazo }\end{array}$ & $\begin{array}{l}\text { Criatividade: relacionada com o } \\
\text { desenvolvimento das capacidades } \\
\text { individuais e coletivas, refletidas em } \\
\text { certo domínio das tecnologias que } \\
\text { utilizam de forma que a implementação } \\
\text { de modificações significativas se torne } \\
\text { endogenamente determinada }\end{array}$ & $\begin{array}{l}\text { Capacidade de Inovar: relacionada com o } \\
\text { desenvolvimento das capacidades individuais e } \\
\text { coletivas, refletidas em certo domínio das } \\
\text { tecnologias utilizadas, de forma que a } \\
\text { implementação de modificações significativas se } \\
\text { torne endogenamente determinada. A criação de } \\
\text { fluxos de conhecimentos científicos e não- } \\
\text { científicos, fruto dos processos "formais" e "não- } \\
\text { formais" de aprendizado, é determinante para a } \\
\text { construção da Capacidade de Inovar. }\end{array}$ \\
\hline $\begin{array}{c}\text { A relação do } \\
\text { desenvolvimento } \\
\text { tecnológico e as "esferas } \\
\text { não-econômicas" }\end{array}$ & $\begin{array}{l}\text { A criatividade se manifesta nas esferas } \\
\text { cultural, política, artística, científica e } \\
\text { produtiva. }\end{array}$ & $\begin{array}{l}\text { Conjunto de instituições que impactam } \\
\text { diretamente ou indiretamente no } \\
\text { desenvolvimento tecnológico, estando } \\
\text { intimamente relacionadas com a criação de } \\
\text { conhecimento (item acima). }\end{array}$ \\
\hline $\begin{array}{c}\text { O desenvolvimento } \\
\text { tecnológico e as } \\
\text { características } \\
\text { idiossincráticas a cada } \\
\text { contexto sociopolítico }\end{array}$ & $\begin{array}{l}\text { Aspecto endógeno: parte das carências } \\
\text { internas para o desenvolvimento das } \\
\text { potencialidades de cada nação. }\end{array}$ & $\begin{array}{l}\text { Aspecto nacional: proximidades geográfica, } \\
\text { cultural e linguística, e a atuação dos estados } \\
\text { nacionais, têm impacto direto no } \\
\text { desenvolvimento tecnológico e é necessária } \\
\text { porque os sistemas apresentam debilidades. }\end{array}$ \\
\hline $\begin{array}{l}\text { O formato da atuação } \\
\text { estatal pró-ativo }\end{array}$ & $\begin{array}{c}\text { Promover os programas de investimento } \\
\text { nos setores entendidos como estratégicos, } \\
\text { garantir o equilíbrio macroeconômico; } \\
\text { destaca-se a questão da "Nova Aliança". }\end{array}$ & $\begin{array}{l}\text { Prover o ambiente favorável às interações entre } \\
\text { os agentes, e a criação de capacidades inovativas. } \\
\text { Utilizam-se instrumentos, normas e } \\
\text { regulamentações de forma coordenada. }\end{array}$ \\
\hline $\begin{array}{l}\text { A preferência por um } \\
\text { conjunto de produtos e } \\
\text { setores, segundo suas } \\
\text { propriedades de } \\
\text { absorver e gerar } \\
\text { progresso técnico. } \\
\end{array}$ & $\begin{array}{l}\text { Atuação do Estado na reestruturação dos } \\
\text { setores-chave (definidos pelas } \\
\text { capacidades de irradiar progresso } \\
\text { técnico) para a constituição de uma } \\
\text { matriz industrial produtiva e articulada: } \\
\text { setor automobilístico, setor de bens de } \\
\text { capital, o setor agrícola e o setor } \\
\text { energético. }\end{array}$ & $\begin{array}{c}\text { Atuação estatal voltada à promoção da eficiência } \\
\text { Schumpeteriana e àqueles setores com potencial } \\
\text { de "irradiar" seus avanços tecnológicos pela } \\
\text { estrutura produtiva. }\end{array}$ \\
\hline
\end{tabular}

Fonte: Elaboração própria

\section{CONSIDERAÇÕES FINAIS}

O presente trabalho buscou fazer uma revisão teórica e uma análise comparativa das contribuições de Fernando Fajnzylber sobre o processo de desenvolvimento econômico latino-americano e a perspectiva analítica neoschumpeteriana representada pelo conceito de Sistemas Nacionais de Inovação. Não entrando no mérito de fazer uma síntese teórica, o trabalho restringiu-se a destacar a proximidade existente no escopo dessas análises e sugerir pontos de convergência e divergência, os quais por sua vez revelam a visão sistêmica da inovação nas contribuições de Fajnzylber.

A abordagem dos Sistemas de Inovação defende o desenvolvimento das capacidades inovativas como elemento construído e acumulado historicamente, sendo determinado pelo amplo conjunto de atores existentes na materialidade social. Assim, procura compreender a influencias desses atores e suas interações ao desenvolvimento dessas capacidades. Já a análise de Fajnzylber tem como objeto central as particularidades do processo de industrialização, traduzidas no conceito de "Industrialização Trunca". A identificação das debilidades desse processo aproximou Fajnzylber da escola neoschumpeteriana e, consequentemente, da abordagem sistêmica, ainda que o termo "Sistemas Nacionais de Inovação", ainda não tivesse sido cunhado, o que só ocorreu no final da década de 1980. 
O texto permitiu deduzir que essa influência foi decisiva à definição do sentido da agenda normatiza da "Nova Industrialização" de Fajnzylber, em especial ao destaque da "criatividade", restringida na América Latina, como a variável-chave para a assimilação e geração de progresso técnico. Nessa linha, ao remeter as causas da debilidade aos aspectos históricos da formação econômica e institucional da região notou-se novamente o alinhamento. Ademais, pode-se notar que implicitamente a Agenda da Nova Industrialização adequa-se ao conceito de eficiência schumpeteriana, por incentivar atividades produtivas com graus elevados de oportunidade tecnológica. Finalmente, as considerações sobre o papel do Estado na promoção do desenvolvimento produtivo e tecnológico também sugerem o alinhamento.

\section{REFERÊNCIAS BIBLIOGRÁFICAS}

BALZAT, Markus. The Theoretical Basis and the Empirical Treatment of National Innovation Systems. Volkswirtschaftliche Discussionsreihe, n. 232, University of Augsburg, Augsburg 2002.

BIELSCHOWSKY, Ricardo. Cinquenta Anos de Pensamento na CEPAL: Uma resenha. In: BIELSCHOWSKY, Ricardo (Org.). Cinquenta Anos de Pensamento na CEPAL: Volume 1. Rio de Janeiro: Record, 2000. Cap. 1. p. 13-68.

. Sixty years of ECLAC: structuralism and neo-structuralism. CEPAL Review, Santiago, n. 97, p.171-192, abr. 2009.

BITTENCOURT, Pablo Felipe; CÁRIO, Sílvio Antônio Ferraz. Sistemas de Inovação: Das raízes no século XIX à análise global contemporânea. In: RAPINI, Márcia Siqueira; SILVA, Leandro Alves; ALBUQUERQUE, Eduardo Motta de (Org.). Economia da Ciência, Tecnologia e Inovação: Fundamentos teóricos e a economia global. Curitiba: Prismas, 2017. Cap. 9. p. 331-370.

CASSIOLATO, José Eduardo; ERBER, Fábio Stefano. Política Industrial: Teoria e prática no Brasil e na OCDE. Revista de Economia Política, São Paulo, v. 17, n. 2, p. 32-60, abr.-jun. 1997.

CASSIOLATO, José Eduardo; LASTRES, Helena Maria Martins. Sistemas Nacionais de Inovação e Desenvolvimento: as implicações de política. São Paulo em Perspectiva, São Paulo, v. 19, n. 1, p. 34-45, jan.-mar. 2005.

CASSIOLATO, José Eduardo; MATOS, Marcelo Pessoa de; LASTRES, Helena Maria Martins. Innovation Systems and Development. In: CURRIE-ALDER, Bruce; KANBUR, Ravi; MALONE, David M.; MEDHORA, Rohinton (Org). International Development: Ideas, experiences and prospects. [s.i]: Oxford University Press, 2014. Cap. 33. Disponível em:

https://www.researchgate.net/publication/299898698_Innovation_Systems_and_Development

CHRISTENSEN, Jesper Lindgaard, GREGERSEN, Birgitte, JOHNSON, Björn, LUNDVALL, Bengt Åke, TOMLINSON, Mark. An NSI in transition? Denmark. In: EDQUIST, Charles. HOMMEN, Leif. Small Country Innovation Systems. Northampton: Edward Elgar, 2008. Cap. 11, p. 403-441.

FAJNZYLBER, Fernando. La Industrialización Trunca de America Latina. Mexico, D.f: Nueva Imagen, 1983.

FERRAZ, João Carlos; PAULA, Germano Mendes de; KUPFER, David. Política Industrial. In: KUPFER, David; HASENCLEVER, Lia (Org.). Economia Industrial: Fundamentos teóricos e práticas no Brasil. 2. ed. Rio de Janeiro: Elsevier, 2013. Cap. 24. p. 313-323.

FONSECA, Pedro. Cezar. Dutra. O Processo de Substituição de Importações. In: REGO, José Márcio; MARQUES, Rosa Maria. (Org.). Formação Econômica do Brasil. 1 ed. São Paulo, Saraiva, 2003, p. 248-282. 
FREEMAN, Christopher. Technology Policy and Economic Performance: Lessons from Japan. London: Pinter Publishers, 1987.

FREEMAN, Christopher; SOETE, Luc. A Economia da Inovação Industrial. Campinas: Editora Unicamp, 2008.

GADELHA, Carlos Augusto Grabois. Política Industrial: Uma visão neo-schumpeteriana sistêmica e estrutural. Revista de Economia Política. São Paulo, v. 21, n. 4, p. 149-171, out.- dez. 2001.

HANUSCH, Horst; PYKA, Andreas. Principles of Neo-Schumpeterian Economics. Cambridge Journal Of Economics, [s.1.], v. 31, n. 2, p.275-289, 20 jul. 2006. Oxford University Press (OUP). http://dx.doi.org/10.1093/cje/bel018.

KIM, L. Da Imitação à Inovação: a dinâmica do aprendizado tecnológico da Coréia. Campinas: Editora Unicamp, 2008

LIST, Georg Friedrich; HODGSKIN, Thomas. Sistema Nacional de Economia Política. São Paulo: Nova Cultural, 1986.

LUNDVALL, Bengt-Åke. National Innovation System: analytical concept and development tool. Industry and Innovation, London, v. 14, n. 1, p.95-119, feb. 2007.

. Innovation as an Interactive Process: From User- Producer Interaction to the National Systems of Innovation. In: LUNDVALL, B. A. (Org.). The Learning Economy and the Economics of Hope. London: Anthem Press, 2016. Cap. 3. p. 61-84.

MARTINS, Marcilene. Padrões de eficiência no comércio: definições e implicações normativas. Nova Economia, Belo Horizonte, v. 18, n. 2, p.293-313, mai.-ago. 2008.

MARX, Karl. Grundrisse: Manuscritos econômicos de 1857 - 1858: Esboços da crítica da economia política. São Paulo: Boitempo, 2011.

MAZZUCATO, Mariana. O Estado Empreendedor: Desmascarando o Mito do Setor Público Vs. o Setor Privado. São Paulo: Portfolio Penguim, 2014. 320 p.

NELSON, Richard. National Innovation Systems: a comparative analysis. New York: Oxford University Press, 1993.

PAIVA, Suzana Cristina Fernandes de. Estratégias de Política Industrial e Desenvolvimento Econômico: Ideias de Ideais de Fernando Fajnzylber para a América 88 Latina. 2006. 308 f. Tese (Doutorado) - Programa de Pós-Graduação em Economia Aplicada, Universidade Estadual de Campinas, Campinas, 2006.

PEREZ, Carlota. Technological revolutions and techno-economic paradigms. Working Papers in Technology Governance and Economic Dynamics, n. 20, Tallinn University of Technology, Tallinn, 2009.

PREBISCH, Raul. O desenvolvimento econômico da América Latina e alguns de seus principais problemas [Manifesto Latino-Americano]. In: GURRIERI, Adolfo (Org.). O Manifesto LatinoAmericano: e outros ensaios. Rio de Janeiro: Contraponto, 2011. Cap. 1. p. 86-152.

RICARDO, David. Princípios de Economia Politica e Tributação. São Paulo: Nova Cultural, 1996. RODRIGUEZ, Octavio. O Estruturalismo Latino-Americano. Rio de Janeiro: Civilização Brasileira, 2009.

SCHUMPETER, Joseph Alois. Teoria do Desenvolvimento Econômico: Uma investigação sobre lucros, capital, crédito, juros e ciclo econômico. São Paulo: Nova Cultural, 1997. 
SHARIF, Naubahar. Emergence and development of the National Innovation Systems concept. Research Policy, New York, v. 35, n. 5, p.745-766, jun. 2006.

SMITH, Adam. A Riqueza das Nações: Investigação sobre sua natureza e suas causas. São Paulo: Nova Cultural, 1996.

SUZIGAN, Wilson; FERNANDES, Suzana Cristina. Competitividade Sistêmica: a contribuição de Fernando Fajnzylber. História Econômica e História de Empresas, São Paulo, v. 7, n. 2, p. 165-187, jul.-dez. 2004.

SUZIGAN, Wilson; FURTADO, João. Política Industrial e Desenvolvimento. Revista de la CEPAL. Santiago, Chile, número especial em português, p. 193-208, 2010.

SZAPIRO, Marina; MATTOS, Marcelo; CASSIOLATO, José Eduardo. Sistemas de Inovação e Desenvolvimento. In: RAPINI, Márcia Siqueira; SILVA, Leandro Alves; ALBUQUERQUE, Eduardo Motta de (Org.). Economia da Ciência, Tecnologia e Inovação: Fundamentos teóricos e a economia global. Curitiba: Prismas, 2017. Cap. 10. p. 371-412

TAVARES, Maria da Conceição. O Processo de substituição de importações como modelo de desenvolvimento na América Latina: O caso Brasil. In: Vanessa Petrelli Corrêa, Monica Simioni. (Org.). Desenvolvimento e Igualdade: Homenagem aos 80 Anos de Maria da Conceição Tavares. Rio de Janeiro: IPEA, 2011. Cap. 3. p. 61-149.

TORRES, Miguel (Comp.). Fernando Fajnzylber: Una visión renovadora del desarrollo de América Latina. Santiago: Cepal, 2006.

VIOTTI, Eduardo B. National learning systems: a new approach on technological change in late industrializing economies and evidences from the cases of Brazil and South Korea. Technological Forecasting and Social Change, v. 69, n. 7, p. 653-680, 2002. 